\title{
AVALIAÇÃO DE CULTIVARES DE CEREAIS DE INVERNO NAS CONDIÇÕES DE BOTUCATU SÃO PAULO
}

\author{
Priscila Gonzales Figueiredo ${ }^{1}$, Sihélio Júlio Silva Cruz ${ }^{2}$, \\ Rodrigo Alberto Repke ${ }^{1}$, Simério Carlos Silva $\mathrm{Cruz}^{2}$, Silvio José Bicudo ${ }^{3}$
}

Resumo: Objetivou-se com este trabalho avaliar o desempenho agronômico de variedades de aveia-preta (Avena strigosa S.), aveia-branca (Avena sativa L.), cevada (Hordeum vulgare sp. Vulgare) e trigo (Triticum aestivum L.) nas condições de Botucatu-SP. Foram realizados quatro experimentos em delineamento experimental de blocos ao acaso, onde os tratamentos foram compostos por diferentes variedades dos seguintes cereais: Experimento I - Aveia preta, o Experimento II - Aveia branca, o Experimento III - Cevada e o Experimento IVTrigo. As variáveis avaliadas foram: o intervalo da emergência ao florescimento, o rendimento de biomassa seca, a produtividade de grãos e a massa de mil grãos. Com base na produção de massa seca pelas variedades de aveia-preta IAPAR 61 Ibiporã, Comum e EMBRAPA 29, as mesmas surgem como boa opção para cobertura do solo em sistema plantio direto. A variedade de aveia-branca Brisasul destacou-se para a utilização como cobertura do solo e forragem, e as variedades UFP a 20 Teixeirinha, UFPA Gaudéria e Barbarasul destacaram-se para a produção de grãos. A variedade de cevada BRS Lagoa destacou-se pela maior produção de biomassa seca e produtividade de grãos. Diante dos baixos desempenhos apresentados pelas três variedades de trigo, as mesmas não são alternativas viáveis para o cultivo de inverno nesta região.

PALAVRAS-CHAVE: Avena sativa L.; Avena strigosa S.; Hordeum vulgare SP. Vulgare; Triticum aestivum $\mathrm{L}$.

\footnotetext{
${ }^{1}$ Doutorando do curso de Agricultura da Faculdade Ciências Agronômicas/UNESP, Avenida José Barbosa de Barros, CxP. 1237 , CEP: 18603-970 - Botucatu - SP - Brasil.

${ }^{2}$ Professor Doutor da Universidade Federal de Goiás, Campus Jataí. BR 364, km 193, CEP: 75801-615 - Jataí GO - Brasil. Email: simerio_cruz@yahoo.com.br.

${ }^{3}$ Professor Doutor do Departamento de Produção Vegetal; UNESP, Avenida José Barbosa de Barros, CxP. 1237 , CEP: 18603-970 - Botucatu - SP - Brasil
}

Revista Agrotecnologia, Anápolis, v. 4, n. 2, p. 43 - 56, 2013 


\title{
Evaluation of varieties of winter cereals in Botucatu São Paulo
}

\begin{abstract}
The objective of this work was to evaluate the agronomic performance of varieties of oat (Avena strigosa S.), oat (Avena sativa L.), barley (Hordeum vulgare sp. Vulgare) and wheat (Triticum aestivum L.) in the conditions of Botucatu-SP. Four experiments were conducted in randomized complete blocks, where the treatments were different varieties of cereals following: Experiment I - Oat, Experiment II - White Oats, Experiment III - Barley and Experiment IV- Wheat. The variables evaluated were: the interval from emergence to flowering, the yield of dry biomass, grain yield and weight of 1000 grains. Based on dry matter production by varieties of oat IAPAR 61 Ibiporã, Common and EMBRAPA 29, they arise as a good option to cover the soil under no-tillage. A variety of white oats Brisasul stood out for use as ground cover and forage, and UFP a 20 Teixeirinha varieties, UFPa Gauderia and Barbarasul highlights were for grain production. The barley variety BRS Pond excelled in greater production of dry biomass and grain yield. Given the low performance shown by the three wheat varieties, they are not feasible for the winter crop alternatives in this region.
\end{abstract}

KEY WORDS: Avena sativa L.; Avena strigosa S.; Hordeum vulgare sp. Vulgare; Triticum aestivum $\mathrm{L}$.

\section{INTRODUÇÃO}

Os cereais de inverno são gramíneas anuais de crescimento ereto, podendo apresentar alturas entre 60 a $150 \mathrm{~cm} \mathrm{e}$ incluem a aveia-branca (Avena sativa L.), o centeio (Secale cereale L.), a cevada (Hordeum vulgare L.), o trigo (Triticum aestivum L.) e o triticale ( $X$. Triticosecale Wittmack). Geralmente são utilizados para produção de grãos, para alimentação humana ou animal, como forragem, ou ainda como cobertura do solo (BALL et al., 2002; AITA; GIACOMINI, 2003; FONTANELI et al., 2009).

No ano de 2013, o Brasil produziu cerca de 381 mil toneladas de aveia, 300 mil toneladas de cevada e 4.814 mil toneladas de trigo, com rendimentos médios de 2,2; 3,2 e $2,2 \mathrm{t} \mathrm{ha}^{-1}$, respectivamente. Esta produção é pequena, tendo em vista a demanda do país por estes cereais (MINELLA, 1999; CONAB, 2013).

O cultivo de cereais de inverno é uma opção para o período março-setembro 
em sucessão às culturas tradicionalmente semeadas no verão. $\mathrm{O}$ cultivo destes cereais no estado de São Paulo, até o início da década de 80 , restringia-se ao Vale do Paranapanema em condições de sequeiro. A partir de 1982, o estabelecimento da cultura irrigada possibilitou o cultivo em todo o Estado (FELICIO et al., 2001).

Entretanto, a produtividade dos cereais não é determinada apenas pelo fator hídrico, segundo Barros e Calado (2012), a baixa produção dos cereais de inverno pode estar associada a fatores intrínsecos (genótipo da planta) e extrínsecos (condições edafoclimáticas) além da interação destes dois fatores. Portanto a avaliação do desempenho de variedades em diferentes ambientes é essencial para a escolha do material mais promissor para cada região (GAMA et al., 2000; RIBEIRO et al., 2000).

Neste sentido, objetivou-se com este trabalho avaliar o desempenho agronômico de variedades de aveia preta (Avena strigosa $\mathrm{S}$ ), aveia branca (Avena sativa L.), cevada (Hordeum vulgare sp. Vulgare) e trigo (Triticum aestivum L.) nas condições de Botucatu-SP.

\section{Material e Métodos}

Foram conduzidos quatro experimentos para avaliar o desempenho agronômico de variedades de aveia preta, aveia branca, cevada e trigo. Os experimentos foram realizados em condições de campo, de maio a setembro de 2011 na Faculdade de Ciências Agronômicas UNESP/Botucatu. A localização geográfica desta área está definida pelas seguintes coordenadas: latitude $22^{\circ} 49^{\prime} 31^{\prime \prime} \mathrm{S}$, longitude $48^{\circ} 25^{\prime} 37^{\prime \prime}$ W Grw e altitude de $770 \mathrm{~m}$. O clima da região de Botucatu é do tipo $\mathrm{Cfa}$, clima temperado quente (mesotérmico) úmido, segundo a classificação de Köppen, e B2rB'3a', clima úmido com pequena deficiência hídrica em abril, julho e agosto segundo a classificação de Thornthwaite (CUNHA; MARTINS, 2009).

O delineamento experimental foi o de blocos ao acaso, onde o Experimento I Aveia preta, foi composto por cinco tratamentos e cinco repetições, o Experimento II - Aveia branca, foi composto por dez tratamentos e três repetições, o Experimento III - Cevada, foi composto por treze tratamentos e três repetições e o Experimento IV- Trigo, foi composto por três tratamentos e seis repetições. A parcela experimental foi composta por 12 linhas de 2,5 m cada espaçadas em $0,17 \mathrm{~m}$, com área total de $4,25 \mathrm{~m}^{2}$, sendo considerada área útil 1,53 $\mathrm{m}^{2}$. 
Os tratamentos foram constituídos por diferentes variedades, a saber: Experimento I (Aveia-preta): CD 2004 0903, CB 2004 0905, IAPAR 61 IBIPORÃ, COMUM e EMBRAPA 29, Experimento II (Aveia-branca): UPF a 20 Teixeirinha, UPF a 22 Temprana, UPFA Gaudéria, UFRGS 19, URS 21, URS Tarimba, Albasul, Barbarasul, Brisasul e IAC 7, Experimento III (Cevada): BRS 180, BRS 195, BRS BOREMA, BRS
MARCIANA, BRS MIRENE, BRS Suabiam, BRS 225, BRS Lagoa, BRS Mariana, Embrapa 128, BRS Cauê, PFC 2001-049 e Experimento VI (Trigo): IAC 24, IAC 373 e CD 116.

Os dados climáticos referentes ao período de condução do experimento foram obtidos no posto meteorológico do Departamento de Recursos Naturais e Ciências Ambientais da FCA/UNESP, Campus de Botucatu (Figura 1).

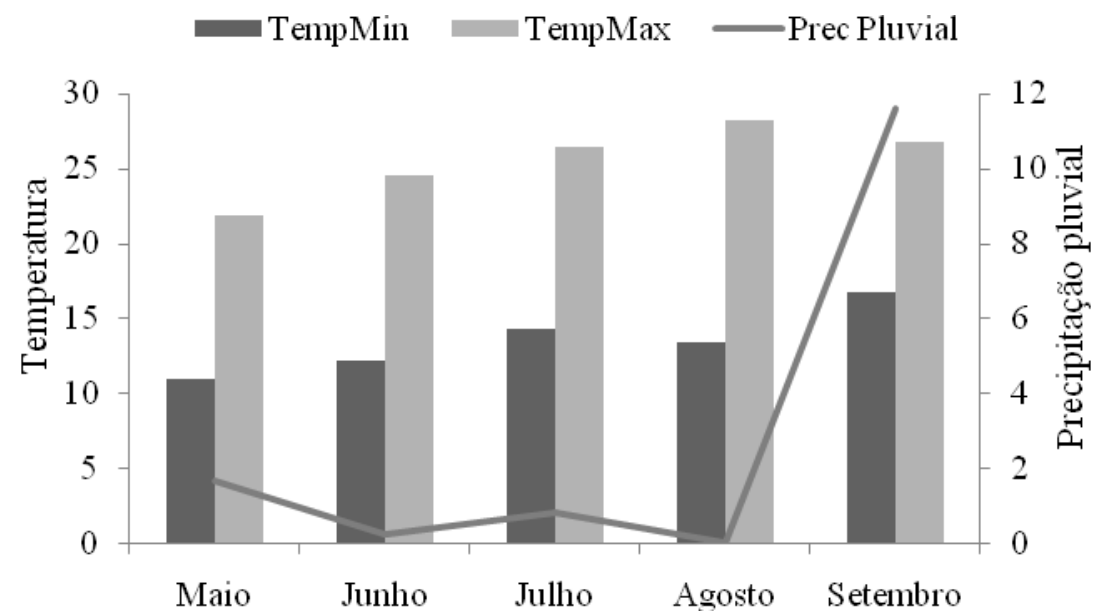

Figura 1 - Temperaturas máximas e mínimas e precipitação pluvial observadas no período de condução dos experimentos no município de Botucatu, ano agrícola 2011.

O solo da área experimental foi classificado como Nitossolo Vermelho distrófico estruturado de textura argilosa (CARVALHO et al., 1983; EMBRAPA, 1999), com as seguintes características químicas (Tabela 1).

O preparo do solo consistiu de duas passadas de enxada rotativa, realizadas após a dessecação de plantas infestantes com Glyphosate na dose de 2,0 $\mathrm{kg} \mathrm{ha}^{-1}$ do produto comercial Roundup WG. Em seguida foi feito o sulcamento e adubação de semeadura, quando foram aplicados 130 $\mathrm{kg} \mathrm{ha}^{-1}$ da fórmula 8-16-24, calculado com base na análise química do solo (Tabela 1) e na recomendação de Raij et al. (1997). A instalação do sistema de irrigação por gotejamento foi realizada logo em seguida. 
FIGUEIREDO, P. G. et al.

Tabela 1 - Atributos químicos do solo na profundidade de 0-20 cm antes da instalação do experimento, Botucatu, ano agrícola 2011.

\begin{tabular}{|c|c|c|c|c|c|c|c|c|c|c|c|}
\hline $\begin{array}{l}\text { Profundidade } \\
\qquad \mathrm{cm}\end{array}$ & $\begin{array}{c}\mathrm{pH} \\
\mathrm{CaCl}_{2}\end{array}$ & $\begin{array}{c}\mathrm{MO} \\
\mathrm{g} \mathrm{dm}^{-3}\end{array}$ & $\begin{array}{l}\mathrm{P} \text { (resina) } \\
\mathrm{mg} \mathrm{dm}^{-3}\end{array}$ & $\mathrm{Al}$ & $\mathrm{H}+\mathrm{Al}$ & $\mathrm{K}$ & $\begin{array}{l}\mathrm{Ca} \\
\mathrm{mms}\end{array}$ & $\begin{array}{r}\mathrm{Mg} \\
\mathrm{l}_{\mathrm{c}} \mathrm{dn}\end{array}$ & SB & CTC & V \\
\hline & 5,2 & 25 & 22 & 0 & 29 & 3,3 & 24 & 10 & 38 & 67 & 57 \\
\hline \multirow[t]{3}{*}{$0-20$} & $S$ & & $\mathrm{Fe}$ & & $\mathrm{Cu}$ & & & Mn & & n & B \\
\hline & \multicolumn{11}{|c|}{$\mathrm{mg} \mathrm{dm}^{-3}$} \\
\hline & 3 & & 22 & & 7,04 & & & 3,7 & & 55 & 0,18 \\
\hline
\end{tabular}

A semeadura foi realizada manualmente, com uma densidade de 70 sementes viáveis $\mathrm{m}^{-1}$. Após a semeadura aplicou-se $50 \mathrm{~mm}$ de água, a fim de umedecer o perfil do solo. Irrigações complementares foram realizadas em intervalos de 72 horas, de modo que ao final do experimento foram aplicados 433 mm de água, conforme recomendação de Ferreira et al. (1973) e Luz et al. (2008).

Foram avaliados: (1) o intervalo da emergência ao florescimento, determinado em dias após a emergência, quando $51 \%$ das plantas da parcela apresentaram o florescimento completo; (2) o rendimento de biomassa seca da parte área das plantas, determinada no momento do florescimento pleno, onde amostras foram coletadas em 0,50 $\mathrm{m}$ de linha, escolhidas ao acaso, em dois pontos da área útil das parcelas. As amostras coletadas foram secas em estufa de ventilação forçada na temperatura de $65^{\circ} \mathrm{C}$ até estabilização de sua massa seca; (3) a produtividade de grãos, através da massa de grãos contidos na área útil das parcelas, transformada em produtividade de grãos em $\mathrm{Mg} \mathrm{ha}^{-1}$ ajustados para $13 \%$ base úmida e massa de 1000 grãos: determinada indiretamente pela média de oito amostras de 100 grãos ajustada para $13 \%$ de umidade de acordo com a metodologia descrita em Brasil (1992).

Os resultados foram submetidos à análise de variância pelo teste $\mathrm{F}$ a $5 \%$ de probabilidade de erro, sendo as médias da aveia-preta e do trigo comparadas pelo teste de Tukey a $5 \%$ de probabilidade e as médias da aveia-branca e cevada comparadas pelo teste de Scott-Knott a 5\% de probabilidade.

\section{RESULTADOS E DISCUSSÃO}

A análise de variância correspondente ao intervalo em dias da 
FIGUEIREDO, P. G. et al.

emergência ao florescimento (DEF), de aveia-preta não apresentam diferenças biomassa seca no florescimento $\left(\mathrm{Mg} \mathrm{ha}^{-1}\right)$, produtividade de grãos $\left(\mathrm{Mg} \mathrm{ha}^{-1}\right)$ e massa significativas quanto à produtividade, e entre as variedades de trigo não existem de mil grãos (g), dos quatro experimentos, diferenças significativas quanto à biomassa encontram-se na Tabela 2. As variedades seca e a massa de mil grãos.

Tabela 2 - Resumo da análise de variância do intervalo em dias da emergência à floração (DEF), biomassa seca no florescimento (BMS), produtividade de grãos (PG) e massa de mil grãos (MG) dos experimentos de aveia-preta, aveia-branca, cevada e trigo. Botucatu, SP, ano agrícola 2011.

\section{Quadrado Médio}

Aveia-preta

Aveia-branca

\begin{tabular}{|c|c|c|c|c|c|c|c|c|c|c|}
\hline F. variação & GL & $\mathrm{DEF}$ & BMS & PG & MG & GL & $\mathrm{DEF}$ & BMS & PG & MG \\
\hline Variedades & 4 & $12,7^{* *}$ & $3,2^{* *}$ & $0,5^{\mathrm{ns}}$ & $0,3^{* *}$ & 9 & $72,6^{* *}$ & $2,9^{* *}$ & $1,0^{* *}$ & $0,7^{*}$ \\
\hline Resíduo & 16 & 2,4 & 0,4 & 0,2 & 0,01 & 18 & 5,8 & 0,20 & 0,1 & 0,2 \\
\hline Média & & 70,0 & 6,2 & 2,6 & 6,8 & & 63,1 & 4,1 & 2,9 & 35,2 \\
\hline \multirow[t]{2}{*}{$\mathrm{CV}(\%)$} & & 1,9 & 9,8 & 15,3 & 1,7 & & 3,8 & 11,1 & 9,8 & 11,1 \\
\hline & \multicolumn{5}{|c|}{ Cevada } & \multicolumn{5}{|c|}{ Trigo } \\
\hline F. variação & GL & $\mathrm{DEF}$ & BMS & PG & MG & GL & DEF & BMS & PG & MG \\
\hline Variedades & 12 & $43,2^{* *}$ & $1,7^{* *}$ & $1,3^{* *}$ & $12,7^{* *}$ & 2 & $186,0^{* *}$ & $1,9^{\mathrm{ns}}$ & $0,3^{* *}$ & $0,4^{\mathrm{ns}}$ \\
\hline Resíduo & 24 & 4,7 & 0,2 & 0,1 & 0,02 & 10 & 5,3 & 0,3 & 0,01 & 0,3 \\
\hline Média & & 66 & 3,7 & 2,1 & 42 & & 58,0 & 3,3 & 1,7 & 36,8 \\
\hline $\mathrm{CV}(\%)$ & & 2,9 & 12,4 & 13,2 & 3,8 & & 3,98 & 20,3 & 5,6 & 13,6 \\
\hline
\end{tabular}

\section{Experimento I - Aveia-preta}

As variedades CD 20040903 e

EMBRAPA 29 apresentaram maior ciclo de desenvolvimento quando comparadas à variedade Comum. A EMBRAPA 29 apresentou maior capacidade de produção de biomassa seca enquanto a CB 2004 0905 apresentou menor capacidade de produção de biomassa seca (Tabela 3). 
FIGUEIREDO, P. G. et al.

Tabela 3 - Dias da emergência à floração (DEF), biomassa seca no florescimento, produtividade de grãos e massa de mil grãos de cinco variedades de aveia-preta. Botucatu, SP, ano agrícola 2011.

\begin{tabular}{lcccc}
\hline \multicolumn{1}{c}{ Variedades } & DEF & $\begin{array}{c}\text { Biomassa seca } \\
\left(\mathrm{Mg} \mathrm{ha}^{-1}\right)\end{array}$ & $\begin{array}{c}\text { Prod. de grãos } \\
\left(\mathrm{Mg} \mathrm{ha}^{-1}\right)\end{array}$ & $\begin{array}{c}\text { Massa de mil grãos } \\
(\mathrm{g})\end{array}$ \\
\hline CD 2004 0903 & $72 \mathrm{a}$ & $5,6 \mathrm{bc}$ & $2,9 \mathrm{a}$ & $17 \mathrm{bc}$ \\
CB 2004 0905 & $70 \mathrm{ab}$ & $5,2 \mathrm{c}$ & $2,7 \mathrm{a}$ & $18 \mathrm{~b}$ \\
IAPAR 61 Ibiporã & $70 \mathrm{ab}$ & $6,5 \mathrm{ab}$ & $2,9 \mathrm{a}$ & $13 \mathrm{~d}$ \\
Comum & $68 \mathrm{~b}$ & $6,3 \mathrm{abc}$ & $2,5 \mathrm{a}$ & $15 \mathrm{c}$ \\
Embrapa 29 & $71 \mathrm{a}$ & $7,3 \mathrm{a}$ & $2,2 \mathrm{a}$ & $21 \mathrm{a}$ \\
\hline Média & 70 & 6,2 & 2,6 & 17 \\
C.V. $(\%)$ & 2,21 & 9,83 & 15,33 & 6,8 \\
\hline
\end{tabular}

Médias seguidas de letras diferentes nas colunas diferem entre si a 5\% de probabilidade pelo teste Tukey.

Apesar das diferenças observadas nas variáveis de dias da emergência à floração (DEF) e produção de biomassa seca, não observou-se diferenças significativas entre as variedades para o componente produtividade de grãos, o qual apresentou uma média de 2,6 $\mathrm{Mg} \mathrm{ha}^{-1}$. A variedade EMBRAPA 29 apresentou maior massa de mil grãos enquanto a cultivar IAPAR 61 Ibiporã apresentou o menor valor para esta variável.

O cultivo da aveia-preta normalmente é realizado para cobertura do solo ou para utilização na alimentação animal, na forma de forragem e feno (PRIMAVESI et al., 2001; NORO et al.,2003; GIVENS et al., 2003; AITA; GIACOMINI, 2003), e por isso normalmente é manejada na época do florescimento, neste sentido a variedade EMBRAPA 29 seria a mais recomendada para a região de Botucatu, por apresentar maior produção de biomassa seca.

Para Fávero et al. (2001) as plantas de cobertura são utilizadas com o objetivo de melhorar da qualidade do solo, devendo-se utilizar espécies, mais resistentes às condições de estresse, que produzam mais biomassa, absorvam mais nutrientes e possam ser manejadas mais facilmente pelos agricultores.

Outro aspecto relevante quanto à aveia-preta refere-se à capacidade que a mesma possui de suprimir a infestação de plantas daninhas. De acordo com Paula et al. (2010) a população de $C$. bonariensis resistente ao glyphosate foi maior em áreas mantidas em pousio do que 
naquelas cultivadas com aveia-preta durante o inverno. Os autores afirmam que as plantas de cobertura exerceram efeito supressor sobre a infestante, facilitando seu controle na pré-semeadura da cultura em sucessão, o que torna esta cultura uma boa opção para cobertura do solo no inverno.

\section{Experimento II - Aveia-branca}

As variedades de aveia-branca IAC 7, UFP a 22 Temprana e Barbarasul apresentaram menor intervalo entre a emergência e o florescimento enquanto a cultivar Brisasul foi a que apresentou maior intervalo (Tabela 4). Menores períodos da fase vegetativa reduzem o período de enchimento de grãos na cultura da aveia, uma vez que uma fase vegetativa longa permite à planta produzir área foliar durante um período mais longo, determinando o teor de reservas de fotoassimilados no colmo que poderão ser translocados para os grãos na fase de enchimento de grãos (STRECK et al., 2006; PELTONEN-SAINIO e RAJALA, 2007). No presente estudo, das três variedades que obtiveram maior produtividade e massa de mil grãos, duas possuíam maior período entre a emergência e o florescimento, são elas: UFP a20 Teixeirinha e a UFPA Gaudéria com 64 e 66 DEF, respectivamente. Estes resultados reforçam o que foi mencionado no parágrafo anterior.

Tabela 4 - Dias da emergência à florescimento (DEF), biomassa seca no florescimento, produtividade de grãos e massa de mil grãos de dez variedades de aveia-branca. Botucatu, SP, 2011.

\begin{tabular}{lcccc}
\hline \multicolumn{1}{c}{ Variedades } & DEF & $\begin{array}{c}\text { Biomassa seca } \\
\left(\mathrm{Mg} \mathrm{ha}^{-1}\right)\end{array}$ & $\begin{array}{c}\text { Prod. de grãos } \\
\left(\mathrm{Mg} \mathrm{ha}^{-1}\right)\end{array}$ & $\begin{array}{c}\text { Massa de mil grãos } \\
(\mathrm{g})\end{array}$ \\
\hline UFP a20 Teixeirinha & $64 \mathrm{a}$ & $4,5 \mathrm{c}$ & $3,3 \mathrm{a}$ & $42 \mathrm{a}$ \\
UFP a 22 Temprana & $57 \mathrm{~b}$ & $3,3 \mathrm{~d}$ & $2,9 \mathrm{~b}$ & $39 \mathrm{a}$ \\
UFPA Gaudéria & $66 \mathrm{a}$ & $3,8 \mathrm{~d}$ & $3,6 \mathrm{a}$ & $42 \mathrm{a}$ \\
UFRGS 19 & $63 \mathrm{a}$ & $3,2 \mathrm{~d}$ & $2,2 \mathrm{c}$ & $33 \mathrm{~b}$ \\
URS 21 & $66 \mathrm{a}$ & $3,5 \mathrm{~d}$ & $3,2 \mathrm{~b}$ & $33 \mathrm{~b}$ \\
URS Tarimba & $65 \mathrm{a}$ & $3,6 \mathrm{~d}$ & $3,0 \mathrm{~b}$ & $34 \mathrm{~b}$ \\
Albasul & $66 \mathrm{a}$ & $5,1 \mathrm{~b}$ & $1,9 \mathrm{c}$ & $32 \mathrm{~b}$ \\
Barbarasul & $56 \mathrm{~b}$ & $4,1 \mathrm{c}$ & $3,7 \mathrm{a}$ & $30 \mathrm{~b}$ \\
Brisasul & $71 \mathrm{a}$ & $6,4 \mathrm{a}$ & $3,0 \mathrm{~b}$ & $32 \mathrm{~b}$ \\
IAC 7 & $57 \mathrm{~b}$ & $3,4 \mathrm{~d}$ & $2,5 \mathrm{c}$ & $35 \mathrm{a}$ \\
\hline Média & 63,1 & 4,1 & 2,9 & 35,2 \\
C.V. $(\%)$ & 1,9 & 9,8 & 15,3 & 1,7 \\
\hline
\end{tabular}

Médias seguidas de letras diferentes nas colunas diferem entre si a 5\% de probabilidade pelo teste de Scott Knot. 
Observou-se diferenças significativas na produção de biomassa seca e produtividade de grãos. A utilização da cultivar Brisasul seria a mais recomendada para a utilização como cobertura do solo e forragem, enquanto as variedades UFP a 20 Teixeirinha, UFPA Gaudéria e Barbarasul seriam a mais recomendada para a produção de grãos, na região de Botucatu. Os valores obtidos neste trabalho para os componentes de produção biomassa seca e produtividade de grãos assemelham-se aqueles obtidos por Floss et al. (2007) no município de Piracicaba, onde os autores citaram que estes valores são satisfatórios para a utilização destes materiais como forragem e feno.

As cultivares UFP a 20 Teixeirinha, UFP a 22 Temprana, UFPA Gaudéria e IAC 7 apresentaram maior massa de mil grãos comparativamente as variedades UFRGS 19, URS 21, URS Tarimba, Albasul, Barbarasul e Brisasul. A massa de mil grãos é uns dos componentes de produtividade mais importantes para ser avaliado, pois frequentemente este componente apresenta correlação com a produtividade de grãos, como pôde ser constatado por Ceccon et al. (2004) estudando população de plantas e adubação nitrogenada na aveia-brana no município de Botucatu, SP.

\section{Experimento III - Cevada}

Todas as variáveis avaliadas para cultivares de cevada apresentaram diferença significativa. As variedades EMBRAPA 129, BRS 195, BRS Borema e BRS Cauê apresentaram o período vegetativo mais longo, as variedades BRS 180, BRS Mirene, BRS Mariana e EMBRAPA 128 apresentaram ciclo intermediário e as cultivares BRS Marciana, BRS Suabia, BRS 225 e BRS Lagoa apresentaram ciclo mais curto. As variedades BRS 195, BRS Lagoa, EMBRAPA 129, BRS Cauê e PFC 2001049 apresentaram maior produção de biomassa seca e dentre estas, apenas a cultivar BRS Lagoa apresentou maior produtividade de grãos, e a BRS 195 a que apresentou menor massa de mil grãos (Tabela 5).

De acordo com Abelelo et al. (2003) a produtividade de grãos é o componente mais importante na cultura da cevada quando se avaliada adaptação de cultivares para determinada região, associada a menor incidência de doenças.

Neste sentido a cultivar BRS Lagoa é a mais recomendada para o município de Botucatu, tendo em vista a sanidade das folhas observada visualmente no campo e seu desempenho quanto à produtividade, 
FIGUEIREDO, P. G. et al.

$396 \mathrm{~kg} \mathrm{ha}^{-1}$ a mais que a média nacional na safra 2013/14, que foi de aproximadamente 3,2 $\mathrm{Mg} \mathrm{ha}^{-1}$ (CONAB, 2013). Todas as demais variedades produziram abaixo da média nacional.

Ao contrário do que aconteceu para a aveia-branca, as variedades de cevada que apresentaram período vegetativo mais longos, obtiveram consequentemente menores produtividade de grãos e a massa de mil grãos (Tabela 5). Isto evidencia que o prolongamento excessivo da fase vegetativa, para algumas espécies, como é o caso da cevada, pode resultar em perdas de produtividade principalmente associadas ao tombamento de plantas. Essa condição também pode levar ao autosombreamento foliar e a um microclima favorável ao desenvolvimento de fungos (Rodrigues et al., 2003).

Tabela 5 - Dias da emergência à floração (DEF), produção de matéria seca no florescimento, produção e grãos e massa de mil grãos de treze variedades de cevada. Botucatu, SP, 2011.

\begin{tabular}{lcccc}
\hline Variedades & DEF & $\begin{array}{c}\text { Biomassa seca } \\
\left(\mathrm{Mg} \mathrm{ha}^{-1}\right)\end{array}$ & $\begin{array}{c}\text { Prod. de grãos } \\
\left(\mathrm{Mg} \mathrm{ha}^{-1}\right)\end{array}$ & $\begin{array}{c}\text { Massa de mil grãos } \\
(\mathrm{g})\end{array}$ \\
\hline BRS 180 & $67 \mathrm{~b}$ & $3,5 \mathrm{~b}$ & $2,2 \mathrm{~b}$ & $37 \mathrm{c}$ \\
BRS 195 & $72 \mathrm{a}$ & $4,5 \mathrm{a}$ & $2,1 \mathrm{~b}$ & $33 \mathrm{~d}$ \\
BRS Borema & $71 \mathrm{a}$ & $3,0 \mathrm{c}$ & $1,9 \mathrm{c}$ & $45 \mathrm{~b}$ \\
BRS Marciana & $62 \mathrm{c}$ & $3,0 \mathrm{c}$ & $1,7 \mathrm{c}$ & $48 \mathrm{a}$ \\
BRS Mirene & $65 \mathrm{~b}$ & $2,6 \mathrm{c}$ & $2,5 \mathrm{~b}$ & $48 \mathrm{a}$ \\
BRS Suabia & $63 \mathrm{c}$ & $3,7 \mathrm{~b}$ & $1,6 \mathrm{c}$ & $49 \mathrm{a}$ \\
BRS 225 & $63 \mathrm{c}$ & $2,5 \mathrm{c}$ & $0,9 \mathrm{~d}$ & $43 \mathrm{c}$ \\
BRS Lagoa & $60 \mathrm{c}$ & $4,2 \mathrm{a}$ & $3,6 \mathrm{a}$ & $42 \mathrm{c}$ \\
BRS Mariana & $67 \mathrm{~b}$ & $3,7 \mathrm{~b}$ & $2,2 \mathrm{~b}$ & $49 \mathrm{a}$ \\
Embrapa 128 & $65 \mathrm{~b}$ & $3,6 \mathrm{~b}$ & $1,3 \mathrm{~d}$ & $38 \mathrm{c}$ \\
Embrapa 129 & $71 \mathrm{a}$ & $4,3 \mathrm{a}$ & $1,9 \mathrm{c}$ & $40 \mathrm{c}$ \\
BRS Cauê & $70 \mathrm{a}$ & $4,2 \mathrm{a}$ & $2,3 \mathrm{~b}$ & $41 \mathrm{c}$ \\
PFC 2001-049 & $64 \mathrm{c}$ & $4,9 \mathrm{a}$ & $2,5 \mathrm{~b}$ & $38 \mathrm{c}$ \\
\hline Média & 66 & 3,7 & 2,1 & 42,3 \\
C.V. (\%) & 2,9 & 12,4 & 13,2 & 3,8 \\
\hline
\end{tabular}

Médias seguidas de letras diferentes nas colunas diferem entre si a $5 \%$ de probabilidade pelo teste de Scott Knot.

\section{Experimento IV - Trigo}

Revista Agrotecnologia, Anápolis, v. 4, n. 2, p. 43 - 56, 2013 
FIGUEIREDO, P. G. et al.

Segundo Bastos (1987), o ciclo das variedades de trigo é expresso em dias da emergência ao florescimento $(50 \%$ das plantas + uma, emergidas) e não em dias da emergência à maturação/colheita, devido à grande ocorrência de doenças nesta fase e/ou às condições de ambiente. Neste sentido pode-se separar as variedades entre precoce (IAC 373), intermediária (CD 116) e tardia (IAC 24) (Tabela 6).

Tabela 6 - Dias da emergência ao florescimento (DEF), biomassa seca no florescimento, produtividade e massa de mil grãos de três variedades de trigo. Botucatu, SP, 2011.

\begin{tabular}{lcccc}
\hline Variedades & DEF & $\begin{array}{c}\text { Biomassa seca } \\
\left(\mathrm{Mg} \mathrm{ha}^{-1}\right)\end{array}$ & $\begin{array}{c}\text { Prod. de grãos } \\
\left(\mathrm{Mg} \mathrm{ha}^{-1}\right)\end{array}$ & $\begin{array}{c}\text { Massa de mil grãos } \\
(\mathrm{g})\end{array}$ \\
\hline IAC 24 & $64 \mathrm{a}$ & $2,7 \mathrm{a}$ & $1,5 \mathrm{c}$ & $3,5 \mathrm{a}$ \\
IAC 373 & $53 \mathrm{c}$ & $3,6 \mathrm{a}$ & $1,8 \mathrm{~b}$ & $3,5 \mathrm{a}$ \\
CD 116 & $57 \mathrm{~b}$ & $3,7 \mathrm{a}$ & $1,9 \mathrm{a}$ & $4,1 \mathrm{a}$ \\
\hline Média & 58,0 & 3,3 & 1,7 & 36,8 \\
C.V. $(\%)$ & 3,98 & 20,3 & 5,6 & 13,6 \\
\hline
\end{tabular}

Médias seguidas de letras diferentes nas colunas diferem entre si a $5 \%$ de probabilidade pelo teste Tukey.

As produtividades de grãos obtidas neste trabalho foram inferiores aquelas observadas por Felicio et al. (2001), em que a média de vinte variedades avaliadas em quatro municípios do estado de São Paulo foi de $3,7 \mathrm{Mg}^{-1}$ e à média nacional de produtividade de grãos que é de 2,2 $\mathrm{Mg} \mathrm{ha}^{-1}$ (CONAB, 2013). Estes resultados podem indicar que as variedades de trigo não apresentam boa adaptação às condições de Botucatu. A variedade IAC 24 apresentou menor produtividade de grãos enquanto a variedade CD 116 apresentou os maiores valores para esta variável.
Não houve diferenças significativas para a produção de biomassa seca e para a massa de mil grãos, 3,3 $\mathrm{t} \mathrm{ha}^{-1}$ e $36,8 \mathrm{~g}$ respectivamente.

\section{CONCLUSÕES}

Com base na produção de massa seca pelas variedades de aveia-preta IAPAR 61 Ibiporã, Comum e EMBRAPA 29, as mesmas surgem como boa opção para cobertura do solo em sistema plantio direto.

A variedade de aveia-branca Brisasul destacou-se para a utilização como 
cobertura do solo e forragem, e as variedades UFP a 20 Teixeirinha, UFPA Gaudéria e Barbarasul destacaram-se para a produção de grãos.

A variedade de cevada BRS Lagoa destacou-se pela maior produção de biomassa seca e produtividade de grãos.

Diante dos baixos desempenhos apresentados pelas três variedades de trigo, as mesmas não são alternativas viáveis para o cultivo de inverno no município de Botucatu.

\section{REFERÊNCIAS}

ABELEDO, L. G.; CALDERINI, D. F.; SLAFER, G. Genetic improvement of barley yield potential and its physiological determinants in Argentina (1944-1998). Euphytica, v.130, p.325 - 334, 2003.

AITA, C.; GIACOMINI, S. J. Decomposição e liberação de nitrogênio de resíduos culturais de plantas de cobertura de solo solteiras e consorciadas. Revista Brasileira de Ciência do Solo, Viçosa, v.27, p.601 - 612, 2003.

BALL, D. M.; HOVELAND, C. S.; LACEFIELD, G. D. Southern forages. 3.ed. Norcross: Potash \& Phosphate Institute, 2002. 322 p.
BARROS, J. F. C; CALADO, J. G.

Itinerário Técnico dos Cereais de

Outono-Inverno. Disponível

em: $<$ http://dspace.uevora.pt/rdpc/bitstream /10174/5074/1/Sebenta-cereais.pdf>.

Acesso em: 15 mar 2012

BASTOS, E. Trigo: da lavoura ao pão.

São Paulo: Ícone Editora, 1987. 95p.

BRASIL. Ministério da Agricultura e

Reforma Agrária. Regras para análise

de sementes. Brasília:

SNDA/DNDV/CLAV, 1992. 365p.

CARVALHO, W. A.; ESPÍNDOLA, C. R.; PACCOLA, A. A. Levantamento de solos da Fazenda Lageado - Estação Experimental "Presidente Médici".

Botucatu: Faculdade de Ciências Agronômicas, Universidade Estadual Paulista, 1983. 95 p. (Boletim Técnico, n. 1).

CECCON, G.; GRASSI, H. F.; BICUDO, S. J.Rendimento de grãos de aveia branca (Avena sativa 1.) em densidades de plantas e doses de nitrogênio. Ciência Rural, Santa Maria, v. 34, n. 6, p. 1723 - 1729, 2004.

CONAB. Companhia Nacional de Abastecimento. Acompanhamento da 
safra brasileira de grãos 2013/2014.

Brasília, v. 1, n.2. 68p. 2013.

CUNHA, A. R.; MARTINS, D.

Classificação climática para os municípios de Botucatu e São Manuel, SP. Irriga, v.14, p.1 - 11, 2009.

\section{EMBRAPA. Centro Nacional de}

Pesquisa de Solos. Sistema brasileiro de classificação de solos. Brasília, DF, 1999. 412 p.

FÁVERO, C.; JUCKSCH, I.; ALVARENGA, R. C.; COSTA, L. M. Modificações na população de plantas espontâneas na presença de adubos verdes. Pesquisa Agropecuária Brasileira, Brasília, v. 36, n. 11, p. 1355 - 1362, 2001.

FELICIO, J. C.; CAMARGO, C. E. O.; GERMANI, R.; GALLO, P. B.; PEREIRA, J. C. V. N. A.; BORTOletTO, N.; PETTINELLI JUNIOR, A. Influência do ambiente no rendimento e na qualidade de grãos de genótipos de trigo com irrigação por aspersão no estado de São Paulo. Bragantia, Piracicaba, v.60, p.111 - 120, 2001.

FERREIRA, P. A.; CARDOSO, A. A.; FERNANDES, B.; PARENTES, A. C. Efeito de diferentes níveis de tensão de umidade no solo sobre a produção do trigo. Revista Ceres, Viçosa, v. 20, p. 129 - 135, 1973.

FLOSS, E. L.; PALHANO, A.; SOARES FILHO, C. V.; PREMAZZI, L. M. Crescimento, produtividade, caracterização e composição química da aveia branca. Acta Scientiarum Animal Science, Maringá, v.29, p.1 - 7, 2007.

FONTANELI, R. S.; SANTOS, H. P.; FONTANELI, R. S. Forrageiras para integração lavoura-pecuária- floresta na região sul - brasileira. Passo Fundo: Embrapa Trigo, 2009. 340p.

GAMA, E. E. G.; PARENTONI, S. N.; PACHECO C. A. P.; OLIVEIRA, A. C.; GUIMARÃES, P. E. O.; SANTOS, M. X. dos. Estabilidade de produção de germoplasma de milho avaliado em diferentes regiões do Brasil. Pesquisa Agropecuária Brasileira, Brasília, v.35, p.1143 - 1149, 2000.

GIVENS, D. I.; DAVIES, T. W., LAVERICK, R. M. Effect of variety, nitrogen fertiliser and various agronomic factors on the nutritive value of husked and naked oats grain. Animal Feed Science and Technology, v.113, p.169 - 181, 2003. 
LUZ, P. H. C.; HERLING, V. R.;

BRAGA, G. J.; NOGUEIRE FILHO, C. M.; FARIA, L. A.; LIMA, C. G. Resposta da aveia-preta (Avena strigosa Schreb) à irrigação por aspersão e adubação nitrogenada. Acta Scientiarium Agronomy, Maringá, v.30, p.421 - 426, 2008.

MINELLA, E. Cevada brasileira: situação \& perspectivas. 1999. Disponível em:< http://www.cnpt.embrapa.br/biblio/p co23.

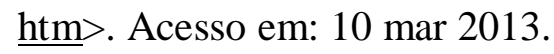

NORO, G; SCHEFFER-BASSO, S. M.; FONTANELI, R. S.; ANDREATTA, E. Gramíneas anuais de inverno para produção de forragem: Avaliação preliminar de cultivares. Agrociência, v.7, p.35 - 40, 2003.

PAULA, J. M. et al. Manejo de Conyza bonariensis resistente ao herbicida glyphosate. Planta Daninha, v. 29, n. 1, p. 217 - 227, 2011.

PELTONEN-SAINIO, P.; RAJALA, A. Duration of vegetative and generative development phases in oat cultivars released since 1921. Field Crops Research, v.101, p.72 - 79, 2007.
PRIMAVESI, A.C.; PRIMAVESI, O.; CHINELATO, A. Indicadores de determinação de cortes de cultivares de Aveia-forrageira. Scientia Agrícola, Piracicaba, v.58, p.79 - 89, 2001.

RAIJ, B.VAN; CANTARELLA, H.; QUAGGIO, J. A.; FURLANI, A. M. C. (Ed.). Recomendações de adubação e calagem para o Estado de São Paulo: Boletim Técnico, 100. 2.ed. Campinas: Instituto Agronômico de Campinas , 1997. $285 p$.

RIBEIRO, P. H. E.; RAMALHO, M. A. P.; FERREIRA, D. F. Adaptabilidade e estabilidade de cultivares de milho avaliadas em diferentes condições ambientais. Pesquisa Agropecuária Brasileira, Brasília, v.35, n.11, p. 213 222, 2000.

RODRIGUES, O.; DIDONET, A. D.; TEIXEIRA, M. C. C.; ROMAN, E. S. Redutores de crescimento. Passo Fundo: Embrapa Trigo, 2003. 18 p.

STRECK, R. A.; BOSCO, N. A. L. C.; MICHELON, S.; WALTER, L. C.; MARCOLIN, E. Duração do ciclo de desenvolvimento de cultivares de arroz em função da emissão de folhas no colmo principal. Ciência Rural, Santa Maria, v.36, p.1086 - 1093, 2006. 